\title{
Virtual Simulation Training and Education in the Context of Mass Entrepreneurship and Innovation
}

\author{
Kaishan Huang, Yongzhang Liu ${ }^{*}$, Liqiong Deng, Lihong Qiu \\ School of Management, Shenzhen University, Shenzhen, China

\section{Email address:} \\ hks@szu.edu.cn (Kaishan Huang),964416759@qq.com (Yongzhang Liu),819343887@qq.com (Liqiong Deng), \\ lihong-qiu@foxmail.com (Lihong Qiu) \\ ${ }^{*}$ Corresponding author
}

\section{To cite this article:}

Kaishan Huang, Yongzhang Liu, Liqiong Deng, Lihong Qiu. Virtual Simulation Training and Education in the Context of Mass Entrepreneurship and Innovation. Science Innovation. Vol. 7, No. 1, 2019, pp. 10-13. doi: 10.11648/j.si.20190701.13

Received: January 20, 2019; Accepted: April 10, 2019; Published: April 28, 2019

\begin{abstract}
In recent years, under the guidance of the policy of "Mass Entrepreneurship and Innovation", the educational institutions have paid more attention to innovation and entrepreneurship education, gradually proposed a variety of innovation and entrepreneurship education means and established some supporting policies for innovation and entrepreneurship education. As a new type of teaching mode, virtual simulation training and education integrates knowledge, creativity and practicability, which can make up for the deficiency of current practical education in management disciplines and promote the development of innovation and entrepreneurship education. Firstly, this paper sorted out the relevant national policy guidelines, further analyzed the content of virtual simulation training and the significance of the model, on this basis, explored several specific measures for the implementation of the model, and elaborated its effectiveness in detail. To promote the development of innovation and entrepreneurship education, virtual simulation training should be integrated into the system, supported by various resources, and the virtual simulation training model should be improved.
\end{abstract}

Keywords: Mass Entrepreneurship and Innovation, Virtual Simulation Training and Education, Teaching Practice

\section{大众创新创业下的虚拟仿真实训教学探索}

黄凯珊, 刘永璋", 邓丽琼, 邱立红

深圳大学管理学院, 深圳, 中国

\section{邮箱}

hks@szu.edu.cn（黄凯珊），964416759@qq.com（刘永璋）, 819343887@qq.com（邓丽琼）, lihong-qiu@foxmail.com（邱立红）

摘要：近年来在国家 “大众创业，万众创新”的政策指引下，全国各高校日益重视创新创业教育，逐步探索出多元有效 的创新创业教育手段, 并建立起了支持创新创业教育的配套机制。虚拟仿真实训作为一种新型的教学模式, 聚知识性、 创造性、实用性于一体，能够弥补当前管理类学科实践教育的不足，促进创新创业教育的发展。本文首先疏理了相关 的国家政策指引, 进一步分析了虚拟仿真实训的内容及其模式的意义,在此基础上探索了该模式实施的几个具体措施, 并对其成效进行了详细阐述。推动创新创业教育发展, 需将虚拟仿真实训纳入体系, 予以多方面资源支持, 完善虚拟 仿真实训模式。

关键词: 大众创新创业, 虚拟仿真, 实践教学 


\section{1. 引言}

近几年来, 国家及教育部大力出台“大众创业, 万众创 新”的相关政策及文件, 在高等学校中开展创新创业教育, 重视实践教学, 提升学生创新能力, 鼓励学生自主创业。 教育部印发的《关于做好 2016 届全国普通高等学校毕业 生就业创业工作的通知》指出, 对有创业意愿的学生, 开 设创业指导及实训类课程; 对已开展创业实践的学生, 进 行企业经营管理类培训; 要广泛举办各类创新创业大赛, 支持高校学生成立创新创业协会、创业俱乐部等社团, 举 办创新创业讲座论坛等。[1]因此, 全国各高校逐步建立起 了创新创业的实践教学教育机制。虚拟仿真实训教学, 作 为创新创业教育的一种新型方式及管理类专业实践教学改 革的重要方向, 聚知识性、挑战性、趣味性、实用性、创 新性于一体, 具有传统教学方式无法比拟的优越性, 弥补 了当前创新创业教育的不足, 提高了人才培养的质量, 促 进了创新创业教育的发展。国家对创新型人才的迫切需要 以及高校实验教学自身内涵发展需求, 虚拟仿真实验教学 已经从“十二五”时期强调虚拟仿真实验教学中心建设、商 业化虚拟仿真实验教学项目集成与局部应用共享为主的初 始普及阶段, 进入到“十三五”时期强调具有自主知识产权 的示范性虚拟仿真实验教学项目建设与大规模在线开放共 享为主的深入发展阶段。[2]本文以“大众创新创业下的虚拟 仿真实训探索”为题, 在梳理了相关创新创业政策下, 对虚 拟仿真实训进行了描述, 归纳总结了七点有效建议。

\section{2. 大众创新下的国家政策指引}

21 世纪是“创新、创业教育的时代”。高等教育改革应 将培养学生的创新精神和实践能力作为全面发展教育改 革的重点。2012年3月, 教育部出台《教育部关于全面提 高高等教育质量的若干意见》中有提出开发创新创业类课 程, 纳入学分管理。2013年5月, 全国普通高校毕业生就 业工作会议为高校开展创新创业教育提供了理论来源和 指导方向。

2014年9月, 李克强总理在夏季达沃斯论坛开幕式中 讲话, 要借改革创新的“东风”, 推动中国经济发展, 在960 万平方公里土地上掀起“大众创业、草根创业”的新浪潮, 形成“万众创新、人人创新”的新态势。

2015年6月，国务院出台《国务院关于大力推进大众创 业万众创新若干政策措施的意见》，推进大众创业、万众 创新, 是发展的动力之源, 有利于稳增长、扩就业、促进 社会纵向流动。[3]2016年3月, 李克强总理在政府报告中指 出, 健全创业人才培养与流动机制, 加快完善创业课程设置, 加强创业实训体系建设。加强创业创新知识普及教育, 使 大众创业、万众创新深入人心。加强创业导师队伍建设, 让一批富有创业精神、勇于承担风险的人才脱颖而出。

\section{3. 虚拟仿真实训简介}

在“大众创业, 万众创新”的时代背景下, 创业创新日 益成为综合国力竞争的制高点, 大学生作为最具创业活力
和潜力的群体, 如何培养其创业创新能力, 是摆在当前社 会发展面前重要紧迫的课题。高校作为大学生创业创新人 才培养的摇篮, 深化高等学校创业创新教育改革, 是国家 实施创新驱动发展战略, 促进经济发展提质增效升级的迫 切需要, 是推进高等教育综合改革, 促进高校毕业生更高 质量创业就业的重要举措。虚拟仿真实训模式, 作为理论 授课、案例教学之后新兴的一种教育模式, 弥补了当前传 统教育的不足, 促进了新型教育的发展。

在国外，虚拟仿真实验教学最早起源于工科类院校基 础课程教学, 如麻省理工学院的微电子在线实验室、美国 北卡罗来纳大学外科手术仿真实室、美国休斯顿大学的虚 拟物理实验室、乔治梅森大学的动态流体虚拟仿真实验系 统等 $[4]$ 。

在中国, 教育部在《国家中长期教育改革和发展规划 纲要（2010-2020年）》指出：信息技术对教育发展具有 革命性的影响, 必须予以高度重视[5]。虚拟仿真实训作为 信息技术化的一种手段, 将虚拟仿真技术与教学模式深度 融合, 在国内高校也受到了空前的重视。虚拟仿真实验教 学综合应用虚拟现实、多媒体、人机交互、数据库以及网 络通讯等技术, 通过构建逼真的实验操作环境和实验对象, 使学生在开放、自主、交互的虚拟环境中开展高效、安全 且经济的实验, 进而达到真实实验不具备或难以实现的教 学效果, 尤其对于那些涉及高危或极端环境、不可及或不 可逆的操作, 以及需要高成本、高消耗的大型或综合性实 验项目, 虚拟仿真实验教学具有明显的优势, 并对传统的 实验教学思想、体系、模式、内容、方法以及手段等都产 生了意义深远的颠覆性影响。可以说, 虚拟仿真实验教学 是高等教育信息化建设的重要内容, 体现出信息技术与教 育教学融合发展和与学科专业深度融合带来的实验教学 改革与创新[6]。

在商科类课程中虚拟仿真实训, 是指学员在讲师的指 导和帮助下, 在虚拟商业环境中, 进行企业创建、企业经 营管理等商业活动的学习演练的过程。其核心架构在“企 业资源规划、分析与经营决策”上, 涉及整体战略、产品 研发、市场与销售、财务、团队沟通与建设等多个方面。

这种实训模式采用体验式、互动式的教学方式融角色 扮演、案例分析和专家诊断于一体, 让学员身临其境, 真 正感受到市场竞争、体验承担经营风险与责任、感悟个性 特点与角色胜任的关联性、培养共赢的理念和坚持诚信原 则信念。通过对“公司”当年业绩的盘点与总结, 反思决策 成败, 解析战略得失, 梳理管理思路, 暴露自身误区, 并 通过多次调整与改进的练习, 切实提高学生综合管理素质。 参加虚拟仿真实训, 不仅可以帮助学习者树立稳固的市场 意识、竞争意识、创新意识, 还可以培养学员的自我意识 和社会意识。

通过基于虚拟仿真实训的创新创业教育模式探索，提 供学生模拟企业经营及竞争的平台, 激发学生自主探索学 习的兴趣, 促进学生理论结合实践能力, 培养学生创新创 业的思维意识, 丰富学生企业经营与管理的创业知识, 提 升学生人际交往能力与分析问题能力, 为今后创新创业成 功打下坚实的基础。 


\section{4. 虚拟仿真实训模式实施探索}

虚拟仿真实训模式, 是一种基于实践的教育理念和教 育活动[7]。其模式实施, 需要强化实践, 以能力培养为核 心, 以创新创业为导向, 从而实现人才培养多元化。[8][9] 根据深圳大学管理教学实验中心在实践教学环节中的摸 索及成果, 现将虚拟仿真实训模式实施的一些措施及成效 整理归纳为以下几条:

\section{1. 获得学校重视, 组织参加各类赛事或研讨会}

虚拟仿真实训模式, 在国内还是一种较为新型的教学 模式, 所以其发展仍需要主要负责的相关教师去推动, 因 此, 获得学校及领导们的认可及重视, 显得尤为重要。管 理教学实验中心负责的老师一方面向领导汇报, 申请资源, 将学生带出去, 另一方面, 积极组织承办各类全国性商业 模拟赛事及研讨会, 将资源引进来。这两种方式都可以得 到资源的扶持, 但相对而言, 后者会体现出这种模式的价 值, 因为举办一次全国性的赛事或研讨会, 在校内要动用 各个部门及资源配合, 需要得到校领导班子的审批及认可 方可启动, 这样就有助于这类型项目在学校的推动及提升 辐射作用。

如: 2016年3月, 深圳大学管理学院承办了由“尖烽时 刻“中国赛区组委会, 深圳大学联合主办的第八届尖烽时 刻“仁盈杯”商业模拟大赛全国总决赛暨教师研讨会, 接待 了来自全国各地的36支参赛队伍共200多位师生。2013年7 月, 由教育部高等学校国家级实验教学示范中心联席会经 济与管理学科组主办、深圳大学承办的“2013全国大学生 管理决策模拟大赛总决赛暨全国经济管理实验教学研讨 会”在深圳大学隆重举行, 来自全国99所高等院校的教师 代表以及270多名参赛学生参加了该项活动。

\section{2. 获得各方经费支持, 组织创建实训平台}

深圳大学从2006年开始, 组织带领学生参加各类虚拟 仿真实训比赛, 从一个沙盘比赛开始, 发展到如今每年组 织参加5-6个全国性比赛，这期间经费问题始终是一个关 键问题。每一项全国性的商业模拟赛事, 基本都需要从校 内选拔赛、省赛、大区复赛、全国决赛甚至全球赛, 一层 一层的不断晋级, 没有经费的支持, 就无法组织带领学生 参与赛事, 也无法让老师们走出去学习最新的教学模式。 因此, 经费在整个模式的推进中提供了相当重要的作用。

近几年, 获得经费的方法, 是坚持不解, 与时俱进 的, 从学院到学校, 从打报告到竞赛项目立项, 一直不 断地在进步。最初参加比赛时, 由带队老师每带一个比 赛向学院打一次报告, 晋级后再继续打报告, 争取经费 支持, 而如今学校已经形成学科竞赛经费支持机制。每 学年初设立学科竞赛项目经费, 以项目立项结题方式, 提供每个赛事申请经费。经统计, 2014年, 深圳大学立 项大学生学科竞赛项目 30 个, 金额共 110 万, 管理教学 实验中心申请立项 3 个 (含 1 个全球赛), 金额达 15 万元。 2015年, 深圳大学立项大学生学科竞赛项目 32 个, 金额 120 万, 管理教学实验中心申请立项 4 个 (含 1 个全球赛), 金额 18 万元。

\section{3. 获得教师资源，建立教师激励机制}

作为虚拟仿真实训的指导教师, 可谓是推动学校实训 模式的中坚力量。这些教师掌握着这个领域尖端的知识体 系, 带领学生参与各类赛事, 指导学生完成各类实验项目, 可以说, 无论是参加商业模拟竞赛指导, 还是进行实践教 学, 都离不开实践教师的组织和指导。因此, 学校必须重 视实训教师队伍建设, 建立相应激励机制。

实训教师队伍的建设, 应该是建设一支数量可观, 结 构合理, 了解社会需求、把握行业发展前沿、能力强、师 德高、相对稳定、专兼结合的实践教学教师队伍。学校采 取切实可行措施, 为其创造良好的环境与氛围。如: 设立 专项资金, 用于实践系列人员参观、学习、培训、交流; 支持高端人才“请进来, 走出去”活动, 加强交流, 扩大视 野; 出资鼓励他们通过国家资格考试获取各种资格证书; 每年对发表高水平实验教学论文或取得相关成果者予以 奖励等。

如今, 深圳大学在虚拟仿真实训方面, 为进一步使本 科学生竞赛管理工作更加科学化、规范化, 鼓励学院积极 开展竞赛活动、优秀教师积极参与竞赛指导, 形成竞赛长 效机制, 给予了教师一些政策倾斜, 如对指导学生获奖的 教师有如实践教学贡献奖或优秀创新团队奖等奖励; 带领 学生获得一定级别全国奖项的工作量还可以替换论文等。 这些措施都有利于稳定实训教师队伍, 提升实训人员教学 能力, 促进实训教学发展和改革。

\section{4. 获得竞赛成绩, 提升校内辐射示范作用}

虚拟仿真实训竞赛成绩, 可以验证项目团队的投入程 度, 也可以为学校学院带来荣誉, 因此, 要及时宣传, 实 时更新, 善于汇总, 获得更多支持和认可, 从而提升校内 辐射示范作用。

自2011年以来, 深圳大学组织带领学生参加国内外各 类商业模拟竞赛, 指导学生参赛团队上千个, 培训指导学 生数上万人次, 获得各类奖项 203 项, 全国性161项, 省级 42项。其中包括:全球奖 5 项、特等奖 18 项, 一等奖47项, 二等奖87项, 三等奖17项, 优秀教师26项, 最佳团队1项, 最佳风采奖1项, 最佳组织奖1项, 最佳创意奖1项等。

\section{5. 建立校企合作关系, 扩大校外辐射示范作用}

学校要大力发展与企业的广泛合作, 将学校与企业有 机结合, 资源共享, 延伸实践教学功能, 扩大校外辐射示 范作用。校企可以通过创新创业项目、情境模拟、案例研 讨、顶岗实习等多种方式开展合作关系, 以实际开展的项 目为中心，通过场景模拟或实际参与，不断积累经验。

校企合作关系的建立, 有助于充分利用社会资源, 有效 提升和加强学生的实务技能和职业素养; 丰富教学素材、教 学资源和教学手段, 提升教学质量, 促进教学模式改革; 互 通有无, 互惠互利, 深化校企合作, 促进资源共享; 依托合 作关系, 向合作单位输送智力资源, 服务社会, 回馈社会。 深圳大学先后与用友新道科技有限公司、金蝶软件有 限公司、上海派金有限公司、深圳市电子商务协会等 20 余个单位建立学生实践教学基地及校企合作关系, 每年接 
纳学生到实习基地进行学习和实践, 大大提高学生实践应 用能力。同时发展包括课程建设、师资培训、社会实践、 教程出版等多方面的专业合作, 缩短学校与社会实际需求 的差距, 让学生适应社会需求。依托校企合作, 实现了专 业学习、行业证书、人才孵化三位一体的有效结合, 引进 实践实验课题。通过校企合作，走“学、研、证”相结合的 道路, 打造理论实践融合的教学模式。

\section{6. 搭建学生社团, 创造创新氛围}

学生社团是大学生展现自己能力的舞台, 也是增长知 识才干的课堂, 具有广泛的参与性。因此, 利用学生社团 组织开展商业模拟竞赛是扩大竞赛参与面、储备优秀参赛 选手、管理和运行实训设备的有效途径。

目前管理教学实验中心已成立的ERP学生俱乐部, 由 中心负责管理, 给予政策支持, 定期组织各类模拟竞赛, 以扩大该类竞赛在学生中的认知度和影响力, 吸引更多学 生了解和走进实验室。另外, 通过以“ERP学生俱乐部”为 代表的学生“小老师”队伍和实验室学生助理方式, 形成了 学生自主管理的实践教学环境, 协助完成实训课程及各类 大赛的组织指导。

\section{7. 结合创新项目, 推广实训成果}

为了贯彻“万众创新、大众创业”科技精神，鼓励和引 导大学生参与科学研究、技术开发、社会实践等创新活动, 学校应鼓励和提供实验实践平台, 支持教师指导学生完成 创业研究、创新创业项目、实验基金项目及教学成果奖等。 这些项目的申请及完成, 有助于促进学生对知识的交融和 应用, 提高学生对商科知识的理解, 提升学生的实验能力, 数据分析能力, 团队配合精神, 增强学生的就业创业能力, 进一步推广实训成果。

近年来, 管理教学实验中心实验教学团队教师, 结合 虚拟仿真实训成果, 完成以及指导学生团队共同完成实验 实践、教研项目 151 项, 其中省级优秀教学成果2项, 校级 教学成果3项，广东省实验室研究会基金项目1项，深圳大 学教改项目 10 项, 深圳大学实验室与设备管理研究基金项 目23项, 深圳大学实验室开放基金项目 82项, 大学生创新 创业项目国家级5项，省级10项，校级15项等。

基于以上虚拟仿真实训的措施, 深圳大学管理学院在 教学实施过程中, 加大了实践教学比重, 改进了实践教学 方法, 激励了学生创业实践, 增强了创新创业教育教学的 开放性、互动性和实效性。模式实施方面, 通过创新创业 项目、商科模拟竞赛、商业演讲、学生社团等方式, 注重 引导学生对企业经营管理能力的训练, 提升学生自主学习、 商业意识、运作能力、团队精神等能力。最终, 将创新意 识、创业精神、创新创业能力等培养融入人才培养体系, 贯穿在模拟实训过程中, 分类施教, 注重素质教育, 扩大 辐射效果, 走可持续发展的道路。

\section{5. 结论}

为了全面贯彻党的十八大和《国家中长期教育改革和 发展规划纲要（2010-2020年）》精神, 切实加强大学生
创新创业教育工作, 深化创新创业教育改革。近年来, 深 圳大学明确提出以创新创业为人才培养的核心目标, 从人 才培养方案制定、专业建设、课程与教材建设、教师队伍 建设、平台建设、经费投入等多方面对加强大学生创新创 业教育提出了明确要求。

虚拟仿真实训模式, 作为一种新兴的创新创业教育模 式, 是培养高级应用型人才的一种重要方式, 是教学改革 中的一种创新体现, 有利于推进高等教育综合改革、促进 高校毕业生更高质量创业就业。管理学院在实施的过程中, 获得初步的成效, 成功应用于实践教学模式中, 较好地提 升了学生特别是商科类学生的管理思维, 自主学习能力, 团队合作能力以及创新创业的能力。因此, 开放视野, 多 方支持, 资源整合, 加大投入, 坚持不解地完善虚拟仿真 实训模式, 更好地推动创新创业教育的可持续发展。

\section{参考文献}

[1] 中华人民共和国教育部.关于做好 2016 届全国普通高等 学校毕业生就业创业工作的通知[Z].2016

[2] 祖强,魏永军.国家级示范性虚拟仿真实验教学项目申报策 略探讨 [J].实验技术与管理,2018,35(09):236-238.

[3] 中华人民共和国国务院.《国务院关于大力推进大众创业万 众创新若干政策措施的意见》 $[Z] .2015$ 。

[4] 黄凯珊, 王小汀.《商业模拟运营竞赛与实践教学相结合的 培养模式探讨》: 李丽. 《基于应用型人才培养的高校教学 改革探索与实践—深圳大学管理学院研究论文集 (5)》[C]. 暨南大学出版社, 2013：33-39。

[5] 中华人民共和国国务院.《国家中长期教育改革和发展规划 纲要 $(2010$ - 2020年)》[Z].2010。

[6] 王卫国.《虚拟仿真实验教学中心建设思考与建议》 [J].实验 室研究与探索, 2013, (12): 5-8。

[7] 滕道明. 职业教育要谨防虚拟仿真实训的泛化 [J]. 职业教 育(中旬刊), 2016(4).

[8] 高晓杰, 曹胜利. 《创新创业教育——培养新时代事业的开拓 者》[J].中国高教研究，2007，（07）：91-93。

[9] 白晟. 虚拟仿真实训系统在教育领域中的应用 $[\mathrm{J}]$. 科技展 望, 2016, 25(12).

[10] 吴涓, 孙岳民, 雷威, 徐春宏, 秦艺汽, 宋爱国. 《东南大 学机电综合虚拟仿真实验教学中心建设规划思路与进展》 [J].实验技术与管理，2014，（10）：5-9。

[11] 韩增芳, 马勍. 《大学生创新创业教育现状调查分析》 [J]. 出国与就业, 2011, (14): 50-51。

[12] 王金岗.《工学结合模式下虚拟仿真教学系统》[J].职教论坛, 2013, (17) : 26-29。 